\title{
Magnetic properties and promising magnetocaloric performances in the antiferromagnetic $\mathrm{GdFe}_{2} \mathrm{Si}_{2}$ compound
}

\author{
Yikun Zhang ${ }^{1,2,3^{*}}$, Jian $\mathrm{Zhu}^{2}$, Shuo $\mathrm{Li}^{2}$, Zhenqian Zhang ${ }^{3}$, Jiang Wang ${ }^{2}$ and Zhongming Ren ${ }^{2}$
}

\begin{abstract}
The magnetocaloric (MC) effect-based solidstate magnetic refrigeration (MR) technology has been recognized as an alternative novel method to the presently commercialized gas compression technology. Searching for suitable candidates with promising MC performances is one of the most urgent tasks. Herein, combined experimental and theoretical investigations on the magnetic properties, magnetic phase transition, and cryogenic MC performances of $\mathrm{GdFe}_{2} \mathrm{Si}_{2}$ have been performed. An unstable antiferromagnetic (AFM) interaction in the ground state has been confirmed in $\mathrm{GdFe}_{2} \mathrm{Si}_{2}$. Moreover, a huge reversible cryogenic MC effect and promising MC performances in $\mathrm{GdFe}_{2} \mathrm{Si}_{2}$ have been observed. The maximum isothermal magnetic entropy change, temperature-averaged entropy change with $2 \mathrm{~K}$ lift, and refrigerant capacity for $\mathrm{GdFe}_{2} \mathrm{Si}_{2}$ were $30.01 \mathrm{~J} \mathrm{~kg}^{-1} \mathrm{~K}^{-1}$, $29.37 \mathrm{~J} \mathrm{~kg}^{-1} \mathrm{~K}^{-1}$, and $328.45 \mathrm{~J} \mathrm{~kg}^{-1}$ at around $8.6 \mathrm{~K}$ with the magnetic change of 0-7 T, respectively. Evidently, the values of these MC parameters for the present AFM compound $\mathrm{GdFe}_{2} \mathrm{Si}_{2}$ are superior to those of most recently reported rareearth-based MC materials, suggesting the potential application for active cryogenic MR.
\end{abstract}

Keywords: rare earths, antiferromagnetic $\mathrm{GdFe}_{2} \mathrm{Si}_{2}$ compound, magnetocaloric performances, cryogenic magnetic refrigeration, magnetic phase transition

\section{INTRODUCTION}

Magnetic materials with promising functional performances have attracted increasing research interests due to their own potential or practical applications in various industries and our daily life aspects [1-10]. The magnetocaloric (MC) effect-based solid-state magnetic refrigeration (MR) technology has been well recognized as an alternative technology to the presently used commercialized gas compression technology [5-9]. The MC effect is an inherent thermodynamic response, and it generally exists in various types of magnetic materials. The magnitudes of the MC effect have a strong correlation with the corresponding magnetic phase transition (MPT); therefore, the investigation of the MC effects of magnetic materials can provide considerable valuable information for the better understanding of MPT [5-9]. Therefore, many magnetic materials have been synthesized and systematically determined with regard to the magnetic proper- ties, MPT, and MC performances not only to search for suitable candidates for active MR application at cryogenic and near room temperature but also to better understand the MPT of magnetic materials [11-25]. However, a large gap still exists at the present stage between the practical MR application requirements and the performances of known MC materials. Thus, exploring suitable candidates with promising MC performances is one of the most urgent tasks.

In the last several decades, investigations have been performed on the MPT and MC effects in the rare-earth (RE)-based materials in amorphous and crystallized states owing to the large magnetic moments of RE ions, which result in considerable MC effects [18-25]. Law and Franco [13] reviewed the MC performances in RE-based high-entropy alloys. Li and Yan [8] summarized several RE-based intermetallic compounds with regard to the structural, magnetic, and MC properties. Similarly, we summarized the magnetic properties and MC performances of $\mathrm{RE}_{2} \mathrm{~T}_{2} \mathrm{X}$ series intermetallic compounds [7]. Li et al. [19] experimentally and theoretically studied the structural, magnetic, and $\mathrm{MC}$ properties of $\mathrm{RE}_{2} \mathrm{ZnMnO}_{6}$ compounds. They observed that $\mathrm{Gd}_{2} \mathrm{ZnMnO}_{6}$ exhibited the largest $\mathrm{MC}$ effect with the peak value of the isothermal magnetic entropy change $\left(-\Delta S_{\mathrm{M}}{ }^{\max }\right)$ up to $25.2 \mathrm{~J} \mathrm{~kg}^{-1}$ under a magnetic field change $(\Delta H)$ of $0-7 \mathrm{~T}$ at around $6.5 \mathrm{~K} \mathrm{[19].} \mathrm{Xu} \mathrm{et} \mathrm{al.} \mathrm{[20]} \mathrm{recently} \mathrm{reported} \mathrm{an}$ $\mathrm{MC}$ effect in ferromagnetic $\mathrm{Sr}_{2} \mathrm{GdNbO}_{6}$ double-perovskite oxide with the $-\Delta S_{\mathrm{M}}{ }^{\max }$ value of $29.7 \mathrm{~J} \mathrm{~kg}^{-1} \mathrm{~K}^{-1}$ under $\Delta H$ of $0-7 \mathrm{~T}$ at around $2 \mathrm{~K}$. In recent years, we have fabricated several series of RE-based materials and checked their magnetic properties, MPT, and MC effects in detail; several of these materials exhibited promising MC performances. For instance, large MC effects in a wide temperature range from the liquefaction temperature of $\mathrm{H}_{2}$ to $\mathrm{N}_{2}$ have been noted in $\mathrm{RE}_{6} \mathrm{Co}_{2} \mathrm{Ga}$ compounds [24]. A table-like MC effect has been achieved in the highentropy $\mathrm{Er}_{20} \mathrm{Ho}_{20} \mathrm{Gd}_{20} \mathrm{Ni}_{20} \mathrm{Co}_{20}$ amorphous alloys [25]. Thus, numerous RE-based materials with potential promising $\mathrm{MC}$ performances deserve to be further investigated.

The ternary RE-based intermetallic compounds with a general composition of $\mathrm{RETM}_{2} \mathrm{X}_{2}(\mathrm{TM}=3 \mathrm{~d}$ transition metals; $\mathrm{X}=\mathrm{P}, \mathrm{As}$, $\mathrm{Si}, \mathrm{Ge}$ ), which mainly crystallize in the layered $\mathrm{ThCr}_{2} \mathrm{Si}_{2}$-type crystal structure belonging to the space group $I 4 / \mathrm{mmm}$, have attracted considerable research interest in recent years [26-32]. Depending on the consistent elementals, various physical properties, such as superconductivity, multilevel MPTs, heavy-

\footnotetext{
${ }^{1}$ School of Electronics and Information Engineering, Hangzhou Dianzi University, Hangzhou 310012, China

${ }^{2}$ State Key Laboratory of Advanced Special Steels \& Shanghai Key Laboratory of Advanced Ferrometallurgy \& School of Materials Science and Engineering, Shanghai University, Shanghai 200444, China

${ }^{3}$ Key Laboratory of Novel Materials for Sensor of Zhejiang Province, Hangzhou Dianzi University, Hangzhou 310012, China

* Corresponding author (email: ykzhang@shu.edu.cn)
} 
fermion behavior, promising thermoelectric performance, and large/giant $\mathrm{MC}$ effects, have been observed [26-32]. The $\mathrm{CeCu}_{2} \mathrm{Si}_{2}$ is the first heavy-fermion superconductor that has shown a multiband behavior and unexpected deficiency of nodal quasiparticles [26,27]. A large reversible anisotropic MC effect has been reported in $\mathrm{EuFe}_{2} \mathrm{As}_{2}$, which is also known as a promising iron-based superconductor candidate [28]. Hou et al. [29] demonstrated that $\mathrm{REMn}_{2} \mathrm{Ge}_{2}$ compounds can host skyrmionic bubbles at room temperature. Several Eu- and Yb-based compounds exhibit low lattice thermal conductivities, which is beneficial for thermoelectric applications [30]. Li et al. [31] reported a giant reversible cryogenic MC effect in $\mathrm{ErMn}_{2} \mathrm{Si}_{2}$ with the $-\Delta S_{\mathrm{M}}{ }^{\max }$ of $25.2 \mathrm{~J} \mathrm{~kg}^{-1} \mathrm{~K}^{-1}$ under $\Delta H$ of $0-5 \mathrm{~T}$ at around $4.5 \mathrm{~K}$, which is related to a second-order MTP (SO-MPT). Moreover, successive MTPs, together with table-like MC effect, have been found in $\mathrm{TbMn}_{2} \mathrm{Si}_{2}$ [32]. Although the $\mathrm{REFe}_{2} \mathrm{Si}_{2}$ series compounds [33-36] were fabricated successfully more than twenty years ago, only some primary physical properties have been reported up to now. Ma et al. [36] studied the magnetic, MPT, and MC properties of $\mathrm{NdFe}_{2} \mathrm{Si}_{2}$ and $\mathrm{PrFe}_{2} \mathrm{Si}_{2}$ compounds, and considerable cryogenic $\mathrm{MC}$ effects were reported with $-\Delta S_{\mathrm{M}}{ }^{\max }$ values of 6.4 and $12.4 \mathrm{~J} \mathrm{~kg}^{-1} \mathrm{~K}^{-1}$ under $\Delta H$ of $0-5 \mathrm{~T}$, respectively. In continuation of our series of studies exploring the RE-based $\mathrm{MC}$ materials and further understanding the physical properties of $\mathrm{RETM}_{2} \mathrm{X}_{2}$ compounds, in this work, a systematic determination of the structural, magnetic properties, MTP, and MC effect in $\mathrm{GdFe}_{2} \mathrm{Si}_{2}$ was performed experimentally and theoretically. A substantial MC effect with the $-\Delta S_{\mathrm{M}}{ }^{\max }$ of $23.25 \mathrm{~J} \mathrm{~kg}^{-1} \mathrm{~K}^{-1}$ under $\Delta H$ of $0-5 \mathrm{~T}$ at around $8.6 \mathrm{~K}$ was achieved in $\mathrm{GdFe}_{2} \mathrm{Si}_{2}$. The present results illustrated that the $\mathrm{GdFe}_{2} \mathrm{Si}_{2}$ possesses excellent cryogenic MC performances and can be a good candidate material for active cryogenic $\mathrm{MR}$ applications.

\section{EXPERIMENTAL AND CALCULATION DETAILS}

The polycrystalline $\mathrm{GdFe}_{2} \mathrm{Si}_{2}$ with a total weight of around $5 \mathrm{~g}$ was fabricated by the conventional arc-melting method. First, the stoichiometric elements $(\mathrm{Gd}, \mathrm{Fe}$, and $\mathrm{Si}$ ) with purities all greater than $99.9 \mathrm{wt} \%$ were directly melted four times under an argon atmosphere. Second, the arc-melted ingot was polished and sealed in a vacuum quartz tube. Then, the quartz tube with the samples was annealed at $880^{\circ} \mathrm{C}$ for six days to improve the homogeneity. Finally, the quartz tube with the samples was directly quenched in ice water. The crystal structure of $\mathrm{GdFe}_{2} \mathrm{Si}_{2}$ was characterized by X-ray diffraction (XRD) technology, and the FULLPROF software [37] was used to perform the refinement. All the samples were stable in the air for up to several months. The magnetic measurements, including the temperature $(T)$ and magnetic field $(H)$ dependences of magnetization $(M)$ for $\mathrm{GdFe}_{2} \mathrm{Si}_{2}$, were performed by using the SQUID magnetometer (MPMS model-7T, Quantum Design).

First-principle calculations on the basis of the density functional theory (DFT) were performed to understand the electronic and magnetic properties of $\mathrm{GdFe}_{2} \mathrm{Si}_{2}$. The standard Vienna $a b$ initio Simulation Package (VASP) [38-40] was employed using plane waves to reproduce one-electron wave functions with an energy cutoff of $520 \mathrm{eV}$ to construct the basis set and project the augmented wave pseudopotentials for the species involved. The $k$-point mesh of $13 \times 13 \times 5$ was applied in all calculations. The valence electron contributions in pseudopotentials were $\left[5 s^{2} 5 p^{6} 4 f^{7} 5 d^{1} 6 s^{2}\right]$ for $\mathrm{Gd},\left[3 p^{6} 3 d^{6} 4 s^{2}\right]$ for $\mathrm{Fe}$, and $\left[3 \mathrm{~s}^{2} 3 \mathrm{p}^{2}\right]$ for Si. The electronic correlation and exchange were modeled by the Perdew-Burke-Ernzerhof functional within the spin-polarized generalized gradient approximation (GGA) [40]. The Hubbard $U$ was introduced into the calculation to improve the on-site Coulomb repulsion of the localized Fe-3d electrons. In addition, the $U_{\text {eff }}=U-J$ was set to $4 \mathrm{eV}$, where $U$ is the Coulomb parameter, and $J$ is Hund's exchange parameter.

\section{RESULTS AND DISCUSSION}

Fig. 1a shows the XRD pattern obtained experimentally at room temperature for $\mathrm{GdFe}_{2} \mathrm{Si}_{2}$ along with the Rietveld refinement by the FULLPROF software [37]. All the diffraction peaks can be well indexed and fitted by using the $\mathrm{ThCr}_{2} \mathrm{Si}_{2}$-type structure (space group of $I 4 / \mathrm{mmm}$ ). The refinement parameters of $R_{\mathrm{F}}$ and $R_{\mathrm{wp}}$ are $1.67 \%$ and $9.02 \%$, respectively, which indicate the high phase purity and crystallographic information of $\mathrm{GdFe}_{2} \mathrm{Si}_{2}$. The lattice parameters $a, b$, and $c$ are 3.9420(9), 3.9420(9), and 9.9895 (3) A, respectively. Fig. 1b-d illustrate the crystal structure and near-neighbor environments of the $\mathrm{GdFe}_{2} \mathrm{Si}_{2}$ compound, in which the $\mathrm{Gd}, \mathrm{Fe}$, and $\mathrm{Si}$ atoms occupy the $2 a, 4 d$, and $4 e$ positions, respectively. Each $\mathrm{Fe}$ atom coordinates with four $\mathrm{Si}$ atoms to form a $\mathrm{FeSi}_{4}$ tetrahedron. $\mathrm{Si}$ atoms exists as squares forming two interlaced layers on both sides of Fe atoms. Thus, the $\mathrm{FeSi}_{4}$ tetrahedra are connected with each other by corner and edge sharing. The $\mathrm{Gd}$ atoms are aligned between the $\mathrm{FeSi}_{4}$ layers. The bond lengths of $\mathrm{GdSi}_{8}$ and $\mathrm{FeSi}_{4}$ units are 2.889 and $2.627 \AA$, respectively.
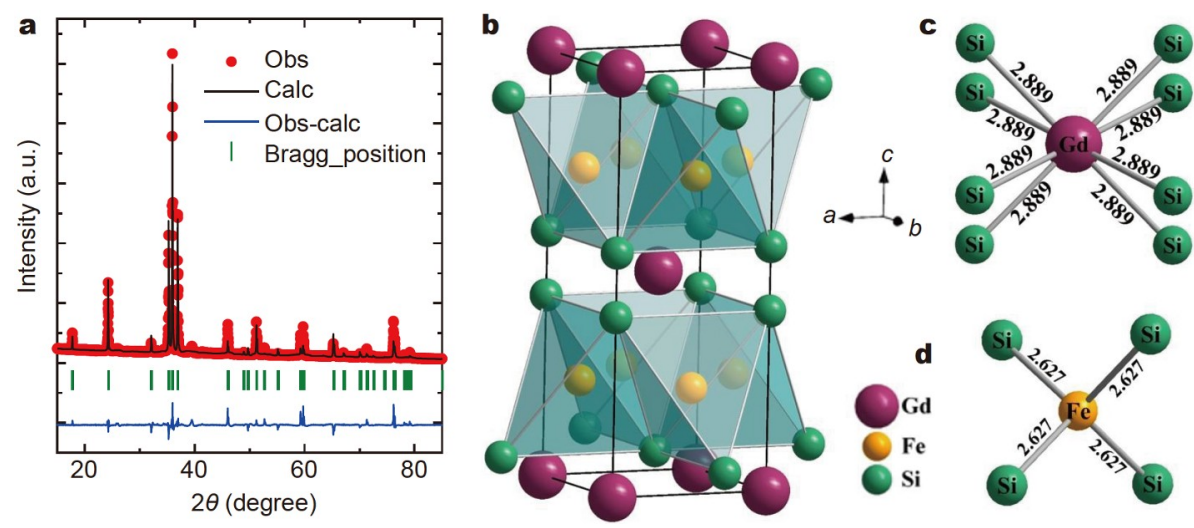

Figure 1 Experimental room-temperature XRD and Rietveld refinement patterns (a), crystal structure (b), and near-neighbor environments of Gd (c) and Fe (d) for $\mathrm{GdFe}_{2} \mathrm{Si}_{2}$. 
To understand the magnetic and MPT properties, we determined the temperature (T)-dependent magnetization $M(T)$ curve (left-scale) and reciprocal susceptibility $(1 / \chi=H / M$, rightscale) for $\mathrm{GdFe}_{2} \mathrm{Si}_{2}$ with the external field $H$ of $1 \mathrm{~T}$ (Fig. 2a). The inset in Fig. 2a gives the $M(T)$ curves for the $\mathrm{GdFe}_{2} \mathrm{Si}_{2}$ compound measured in terms of field cooling (FC) and zero-FC (ZFC) protocols with the $H$ of $0.1 \mathrm{~T}$. The value of $M$ increased monotonously with the decrease in temperature and showed a sharp peak at around $8.6 \mathrm{~K}$, which then decreased continuously with the further decrease in temperature. These results suggest a typical long-range MPT from paramagnetic (PM) to antiferromagnetic (AFM) state. Moreover, the FC and ZFC $M(T)$ curves for $\mathrm{GdFe}_{2} \mathrm{Si}_{2}$ overlapped well in the whole measured temperature regime, and thus, no thermal hysteresis can be observed during their MPT in $\mathrm{GdFe}_{2} \mathrm{Si}_{2}$, which is desirable for practical MR applications. Additionally, the $1 / \chi(T)$ curve above $20 \mathrm{~K}$ showed a linear character, i.e., it followed the Curie-Weiss law: $\chi(T)=C /\left(T-\theta_{\mathrm{P}}\right)$, where $C$ denotes the Curie constant with $C=N\left(\mu_{\mathrm{B}} \mu_{\mathrm{eff}}\right)^{2} / 3 \kappa_{\mathrm{B}}\left(\mu_{\mathrm{eff}}\right.$ refers to the effective magnetic moment, and $\kappa_{\mathrm{B}}$ is the Boltzmann constant), and $\theta_{\mathrm{P}}$ indicates the PM Curie temperature $\left(T_{\mathrm{c}}\right)$. Their linear fits yield a negative $\theta_{\mathrm{P}}$ value of -1.26 , which further confirms the AFM interaction at the ground state. The $\mu_{\text {eff }}$ value of $8.44 \mu_{\mathrm{B}} \mathrm{f} . \mathrm{u}^{-1}$, which is larger than that of the theoretical calculated free $\mathrm{Gd}^{3+}$ ions $\left(7.94 \mu_{\mathrm{B}}\right)$, indicates that the contribution of Fe could not be ignored. In general, the total $\mu_{\text {eff }}$ values can be evaluated by the equation $\mu_{\text {eff }}($ calc $)=\left[\mu_{\mathrm{B}}(\mathrm{RE})^{2}+2 \mu_{\mathrm{B}}(\mathrm{Fe})^{2}\right]^{1 / 2}$, by setting the $\mu_{\text {eff value for }}$ free $\mathrm{Gd}^{3+}$ to $7.94 \mu_{\mathrm{B}}$. The $\mu_{\text {eff }}$ value per Fe ion in $\mathrm{GdFe}_{2} \mathrm{Si}_{2}$ was
$2.02 \mu_{\mathrm{B}}$. Fig. $2 \mathrm{~b}$ presents the $M(T)$ curves in FC protocols under several selected magnetic fields from 0.3 to $4 \mathrm{~T}$ for $\mathrm{GdFe}_{2} \mathrm{Si}_{2}$, which are also in good agreement with the unstable AFM ground state. These experimentally observed magnetic properties for $\mathrm{GdFe}_{2} \mathrm{Si}_{2}$ are consistent with those attained below the theoretically calculated results.

To further identify the magnetic and MPT properties of $\mathrm{GdFe}_{2} \mathrm{Si}_{2}$, we measured the series isothermal magnetization $M(H)$ and illustrated the curves in Fig. 2c. The value of $M$ increased linearly with the increase in $H$ up to $2 \mathrm{~T}$ at low temperatures and showed a saturation-like effect under a high magnetic field. The magnetic moment reached $7.73 \mu_{\mathrm{B}}$ per formula. A large reversible MC effect was expected around the transition temperature since $M$ is sensitive to the magnetic field and temperature, and a large $M$ value can be inspired at low temperatures. Additionally, the MC effect of magnetic materials has strong relationships with the corresponding MPT. Therefore, the order type of MPT for $\mathrm{GdFe}_{2} \mathrm{Si}_{2}$ was further confirmed based on the Banerjee criterion [41] by using the Arrott plots $\left(H / M\right.$ vs. $\left.M^{2}\right)$, as presented in Fig. 2d, which were directly transferred from the $M(H)$ curves. In principle, the negative or positive slopes in the $M^{2} v s$. $H / M$ plots are indicative of a firstorder (FO)- or SO-MPT for a magnetic material. The Arrott plots at low temperatures showed significantly negative slopes as illustrated in Fig. 2d, proving the FO-MPT nature of $\mathrm{GdFe}_{2} \mathrm{Si}_{2}$ at low temperatures.

The $a b$ initio calculations based on DFT were also performed to further understand the magnetic and electronic structures at
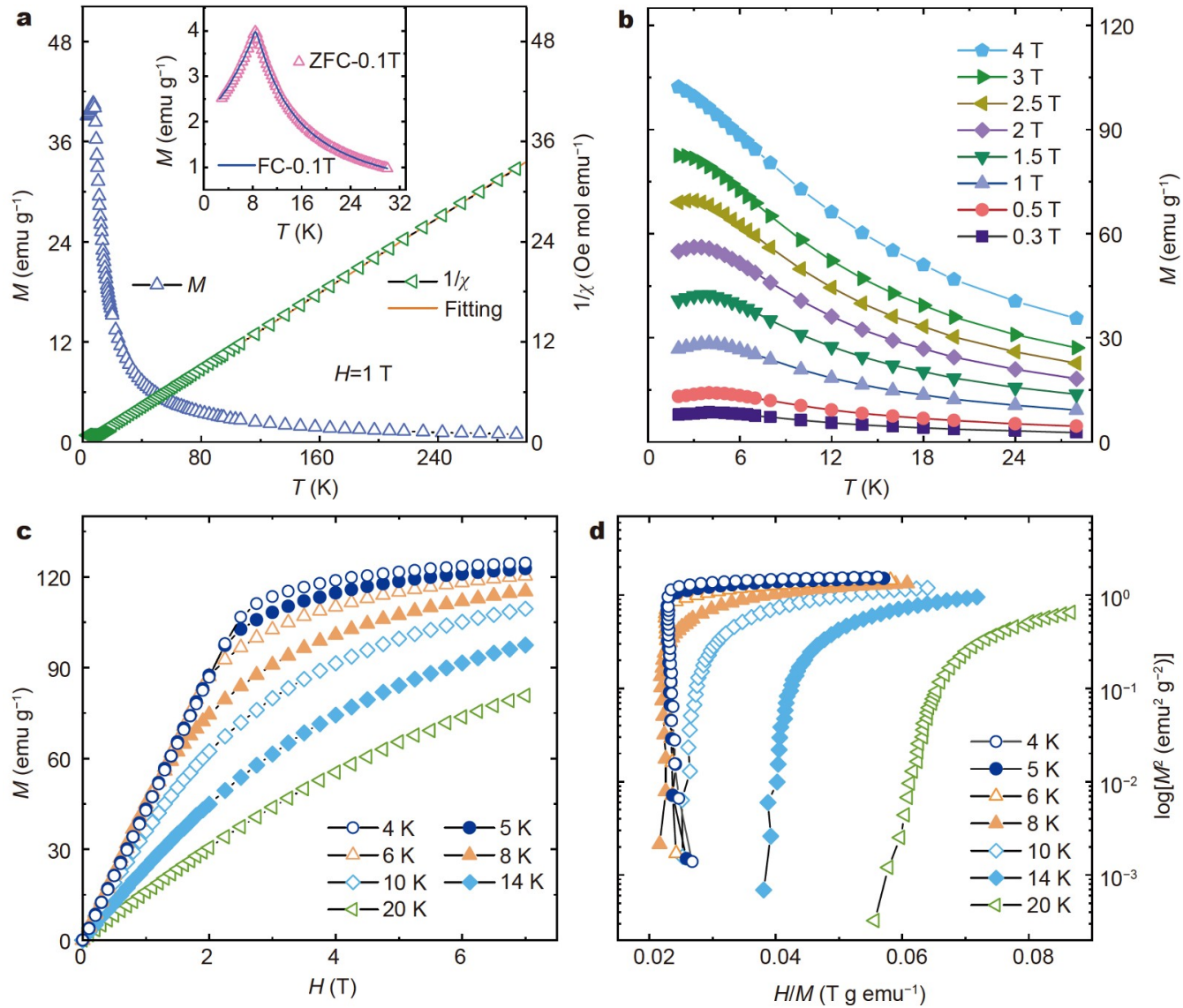

Figure $2 M(T)$ (left-axis) and $1 / \chi(T)$ (right-axis) curves under $H$ of $1 \mathrm{~T}(\mathrm{a}), M(T)$ curves under various magnetic fields (b), and $M(H)$ (c) and Arrott plot $\left(H / M\right.$ vs. $\left.M^{2}\right)$ curves (d) for $\mathrm{GdFe}_{2} \mathrm{Si}_{2}$. Inset in (a) presents the $M(T)$ curves with $\mathrm{ZFC}$ and $\mathrm{FC}$ modes under $0.01 \mathrm{~T}$ for $\mathrm{GdFe}_{2} \mathrm{Si}_{2}$. 
the ground state by GGA and GGA + U methods [38-40]. Four magnetic configurations based on different atomic positions in the unit cell have been considered, which are demonstrated in Fig. $3 \mathrm{a}$ for the FM coupling and in Fig. 3c-e for various AFM couplings. The calculated total energies $\left(E_{\text {tot }}\right)$ were $-44.7383(8)$, $-44.7349(9),-44.7352(5)$, and $-44.7508(7) \mathrm{eV} \mathrm{f.u} .^{-1}$ for the above four magnetic structures. Notably, the differences in $E_{\text {tot }}$ among different magnetic coupling types were well above the error of theoretical calculation, which is at the level of $10^{-6} \mathrm{eV}$, and the $E_{\text {tot }}$ for the AFM (IV-type) was lower than that of FM coupling, indicating an unstable AFM ground state for $\mathrm{GdFe}_{2} \mathrm{Si}_{2}$. Furthermore, the atomic magnetic moments were $6.942 \mu_{\mathrm{B}}$ for Gd and 2.727 and $-2.782 \mu_{\mathrm{B}}$ for Fe. The ground-state total magnetic moment was $6.848 \mu_{\mathrm{B}} \mathrm{f}_{\mathrm{u}} \mathrm{u}^{-1}$. Fig. 3e shows the charge density of $\mathrm{GdFe}_{2} \mathrm{Si}_{2}$, which describes the charge distribution around atoms. Remarkably, a great deal of charge accumulated around $\mathrm{Gd}$ and $\mathrm{Fe}$ atoms, and the localized charge offered Gd and $\mathrm{Fe}$ atoms a large magnetic moment. A small amount of charges were distributed between $\mathrm{Fe}$ and $\mathrm{Si}$ atoms, which led to the formation of a chemical bond between $\mathrm{Fe}$ and $\mathrm{Si}$. The $\mathrm{Fe}$ atoms in different layers bonded in opposite directions with $\mathrm{Si}$ atoms because the Si layer lay between two Fe layers. The reason is probably the AFM coupling of Fe atoms. Furthermore, the total and partial density of states (DOS) were calculated by $a b$ initio calculations based on the AFM coupling, and the illustrations for GGA and GGA $+U$ methods are provided in
Fig. 3f, g, respectively. Notably, regardless of using GGA or GGA $+U$ method, the total DOS was continuous at the Fermi level, indicating the metal nature of the electronic structure of $\mathrm{GdFe}_{2} \mathrm{Si}_{2}$. Then, the metallic characteristic was confirmed by the d-orbit partial DOS of Fe atom. The f-orbit partial DOS of Gd atom was mainly distributed within -4.302 to $-3.765 \mathrm{eV}$ below and $0.638-1.712 \mathrm{eV}$ above the Fermi level. Moreover, the magnetic moment of $\mathrm{Gd}$ atoms was close to the theoretical value $\left(7 \mu_{\mathrm{B}}\right)$. The d-orbit partial DOS of $\mathrm{Fe}$ atom was continuous. However, the peaks moved from $-3.021-0.412 \mathrm{eV}$ by GGA to -6.074 to $-3.604 \mathrm{eV}$ by GGA $+U$. Moreover, the partial DOS of the Fe atom was symmetrical in spin up and down states, which indicated the AFM coupling between adjacent Fe atom layers. In addition, a splitting behavior was observed, demonstrating the magnetic contribution of $\mathrm{Fe}$ atoms for $\mathrm{GdFe}_{2} \mathrm{Si}_{2}$. Thus, reasonable magnetic and electronic properties consistent with the observed experimental results were successfully obtained based on the DFT calculations, which further proved the unstable AFM coupling at the ground state and large magnetic moment of $\mathrm{GdFe}_{2} \mathrm{Si}_{2}$.

In general, the determination of the MC effect is primarily based on the estimation of the magnetic field change $(\Delta H)$ and temperature $(T)$ dependence of isothermal magnetic entropy change, $\Delta S_{\mathrm{M}}(T, \Delta H)$, which can be evaluated indirectly from the $M(T, H)$ curves based on the Maxwell thermodynamic relation [6-8]:
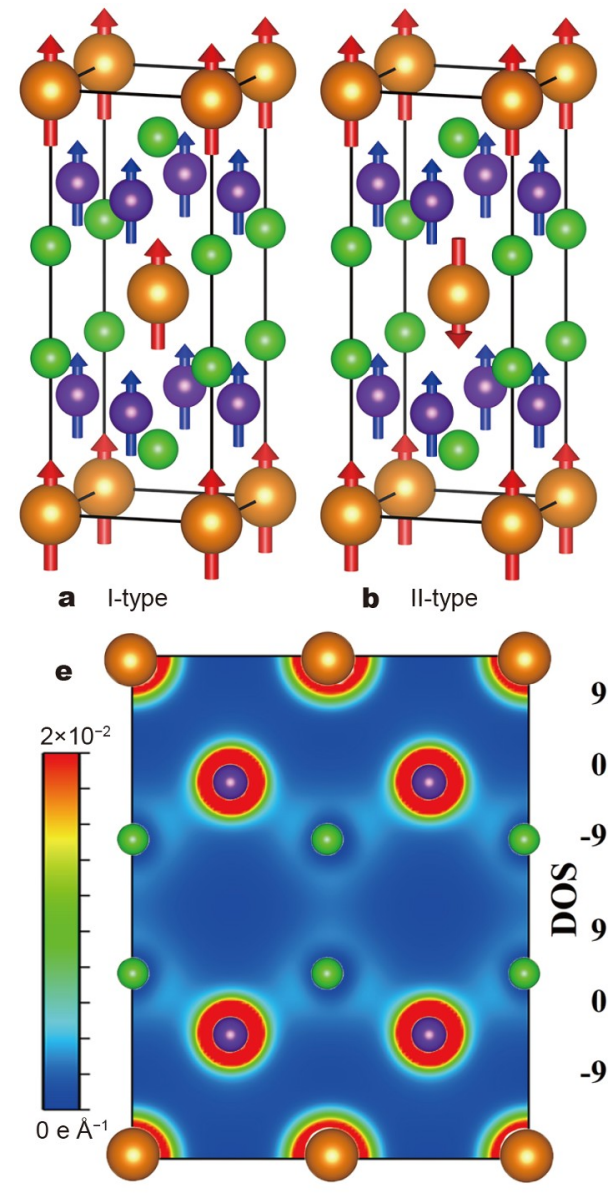

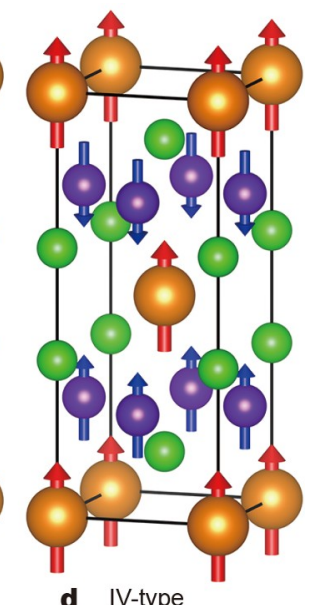

c III-type

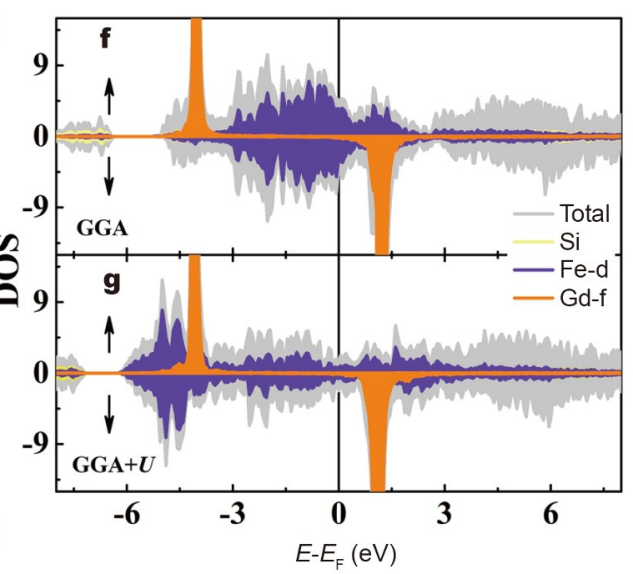

Figure 3 Four potential magnetic structures (a-d), charge density (e), and the DOS at ground state obtained by GGA (f) and GGA $+U$ (g) methods for $\mathrm{GdFe}_{2} \mathrm{Si}_{2}$. 


$$
\Delta S_{\mathrm{M}}(T, H)=S_{\mathrm{M}}(T, H)-S_{\mathrm{M}}(T, 0)=\int_{0}^{H}\left(\frac{\partial M(T, H)}{\partial T}\right)_{H} \mathrm{~d} H .
$$

Fig. 4a illustrates the evaluated $-\Delta S_{\mathrm{M}}(T)$ curves for $\mathrm{GdFe}_{2} \mathrm{Si}_{2}$, with $\Delta H$ values of up to $0-7 \mathrm{~T}$. The $-\Delta S_{\mathrm{M}}$ values were negative at the low-temperature region with $\Delta H$ of $0-1$ and $0-2 \mathrm{~T}$, consistent with the inverse MC effect in the AFM region. Meanwhile, the maximum value of positive $-\Delta S_{\mathrm{M}}\left(-\Delta S_{\mathrm{M}}{ }^{\max }\right)$ for $\mathrm{GdFe}_{2} \mathrm{Si}_{2}$ increased linearly with the increase in $\Delta H$, as presented in Fig. $4 \mathrm{~b}$. The values of $-\Delta S_{\mathrm{M}}{ }^{\max }$ were as high as $7.73,23.25$, and $30.01 \mathrm{~J} \mathrm{~kg}^{-1} \mathrm{~K}^{-1}$ at the $\Delta H$ values of $0-2,0-5$, and $0-7 \mathrm{~T}$, respectively. A magnetic field higher than $2 \mathrm{~T}$ is difficult to generate when using a commercial permanent magnet. The practical application of the moderate value of $-\Delta S_{\mathrm{M}}{ }^{\max }$ with $\Delta H$ of $0-2 \mathrm{~T}\left(7.73 \mathrm{~J} \mathrm{~kg}^{-1} \mathrm{~K}^{-1}\right)$ will be limited by the use of a permanent magnet. Meanwhile, other figures of merit for $\mathrm{GdFe}_{2} \mathrm{Si}_{2}$ were used to check the performances of MC materials, including the temperature-averaged entropy change (TEC, as given in Equation (2)) [42], refrigerant capacity (RC, as given in Equation (3)) [6-8], and relative cooling power (RCP, as given in Equation (4)) [6-8] which have also been determined.

$$
\begin{aligned}
& \operatorname{TEC}\left(\Delta T_{\text {lift }}\right)=\frac{1}{\Delta T_{\text {lift }}}\left\{\int_{T_{\text {mid }}}^{T_{\text {mid }}+\frac{\Delta T_{\text {lift }}}{2}} \Delta S_{M}(T)_{\Delta H, T} \mathrm{~d} T\right\}, \\
& \operatorname{RC}=\int_{T_{\text {cold }}}^{T_{\text {hot }}}\left|\Delta S_{\mathrm{M}}(T)\right| \mathrm{d} T,
\end{aligned}
$$

$$
\mathrm{RCP}=\left|\Delta S_{\mathrm{M}}^{\max }\right| \times \delta T_{\mathrm{FWHM}} \text {. }
$$

In general, the TEC considers the mean $\Delta S_{\mathrm{M}}$ with a certain temperature lift $\left(\Delta T_{\text {lift }}\right)$, and $T_{\text {mid }}$ is the temperature at the center of the average and selected largest value for each $\Delta T_{\text {lift. }}$ Fig. $4 \mathrm{~b}$ presents the resulting values of TEC(2) and TEC(5) as a function of $\Delta H$. Similar $\Delta H$-dependent trends of TEC(2), TEC(5), and $-\Delta S_{\mathrm{M}}{ }^{\max }$ for $\mathrm{GdFe}_{2} \mathrm{Si}_{2}$ can be observed. The obtained values of TEC(2)/TEC(5) were as high as 22.62/21.01 and 29.37/ $27.74 \mathrm{~J} \mathrm{~kg}^{-1} \mathrm{~K}^{-1}$ at the $\Delta H$ of $0-5$ and $0-7 \mathrm{~T}$, respectively. Evidently, the values of TEC(2) were notably closer to the corresponding $-\Delta S_{M}{ }^{\max }$ compared with the values of TEC(5), and this finding was ascribed to the slightly narrow peak width. Thus, a small $\Delta T_{\text {lift }}$ will result in less reduction of the TEC. The RC and RCP are well-known correlated factors [6-8] that enabled us to roughly estimate the amounts of energy that can be transferred in an ideal MR cycle between the hot and cold ends. The integration limits ( $T_{\text {cold }}$ and $T_{\text {hot }}$ ) represent the two sides at $1 / 2\left|\Delta S_{\mathrm{M}}{ }^{\max }\right|$ value of the $-\Delta S_{\mathrm{M}}(T)$ profile and $\delta T_{\mathrm{FWHM}}\left(=T_{\text {hot }}-\right.$ $T_{\text {cold }}$ ). Fig. $4 \mathrm{~b}$ shows the values of RC and RCP as a function of the $\Delta H$. Significantly, the RC and RCP values showed similar increasing tendencies with the continuous increase in $\Delta H$. The obtained RC/RCP values were 205.67/276.56 and $328.45 / 441.72 \mathrm{~J} \mathrm{~kg}^{-1}$ for $\mathrm{GdFe}_{2} \mathrm{Si}_{2}$ at the $\Delta H$ of $0-2$ and $0-7 \mathrm{~T}$, respectively. Table 1 summarizes the MC parameters, including the values of $\Delta S_{\mathrm{M}}{ }^{\max }$, TEC(5), and RCP/RC with $\Delta H$ of $0-5 \mathrm{~T}$ for $\mathrm{GdFe}_{2} \mathrm{Si}_{2}$ together with several known reported RE-based cryo-
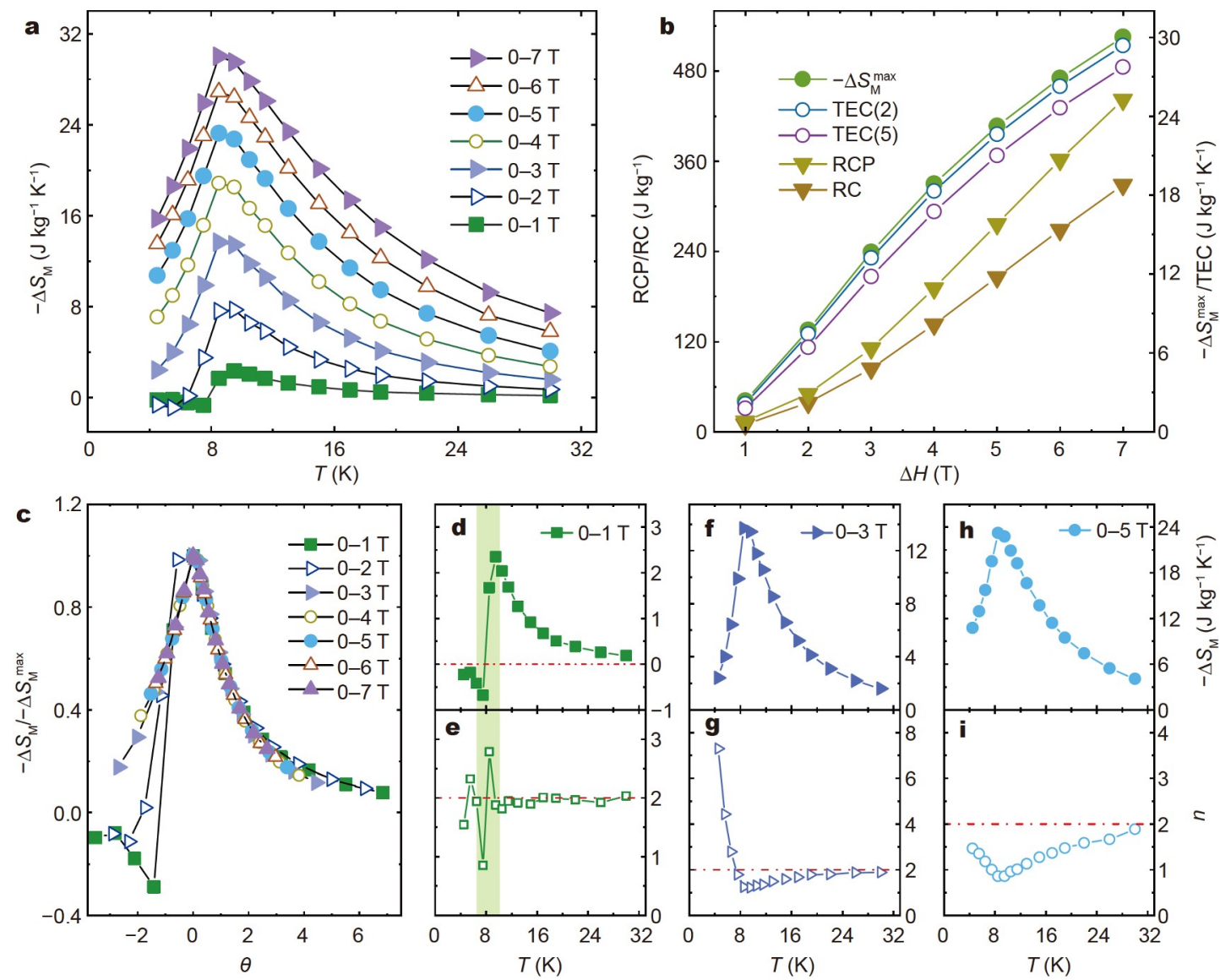

Figure $4-\Delta S_{\mathrm{M}}(T)$ curves with $\Delta H$ from 0-1 to 0-7 T (a), magnetic field change $\Delta H$ dependence of TEC(2)/TEC(5) and $-\Delta S_{\mathrm{M}}{ }^{\max }$ together with the RCP and RC (b), $\left(\Delta S_{\mathrm{M}}(T) / \Delta S_{\mathrm{M}}{ }^{\max }\right) v s$. rescaled temperature $(\theta)$ curves (c), and $-\Delta S_{\mathrm{M}}(T)$ and the corresponding exponent $n$ at the $\Delta H$ of $0-1,0-3$, and $0-5 \mathrm{~T}(\mathrm{~d}-\mathrm{i})$ for $\mathrm{GdFe}_{2} \mathrm{Si}_{2}$. 
Table 1 MC parameters of $\Delta S_{\mathrm{M}}^{\max }, \mathrm{TEC}(5)$, and RCP/RC with $\Delta H$ of $0-5 \mathrm{~T}$ for $\mathrm{GdFe}_{2} \mathrm{Si}_{2}$ and several recently reported popular RE-based cryogenic MC materials at $T_{\mathrm{M}}$ around $8 \mathrm{~K}$. "-" means not provided in the references.

\begin{tabular}{|c|c|c|c|c|c|c|}
\hline Material & $T_{\mathrm{M}}(\mathrm{K})$ & $-S_{\mathrm{M}}^{\max }\left(\mathrm{J} \mathrm{kg}^{-1} \mathrm{~K}^{-1}\right)$ & $\operatorname{TEC}(5)\left(\mathrm{J} \mathrm{kg}^{-1} \mathrm{~K}^{-1}\right)$ & $\operatorname{RCP}\left(\mathrm{J} \mathrm{kg}^{-1}\right)$ & $\mathrm{RC}\left(\mathrm{J} \mathrm{kg}^{-1}\right)$ & Reference \\
\hline $\mathrm{GdFe}_{2} \mathrm{Si}_{2}$ & 8.6 & 23.25 & 21.01 & 276.56 & 205.67 & This work \\
\hline $\mathrm{Gd}_{2} \mathrm{FeAlO}_{6}$ & 2.0 & 18.5 & - & 171.2 & 136.1 & [43] \\
\hline $\mathrm{Sr}_{2} \mathrm{GdNbO}_{6}$ & 2.0 & 26.07 & 19.02 & 195.5 & 148.2 & [20] \\
\hline $\mathrm{TmCoSi}$ & 4.4 & 22.1 & - & 312.1 & - & {$[44]$} \\
\hline $\mathrm{ErMn}_{2} \mathrm{Si}_{2}$ & 5.4 & 25.2 & - & 365 & - & {$[32]$} \\
\hline $\mathrm{Gd}_{2} \mathrm{ZnMnO}_{6}$ & 6.4 & 15.17 & 12.38 & 226.2 & - & [19] \\
\hline $\mathrm{DyCo}_{2} \mathrm{~B}_{2} \mathrm{C}$ & 7.7 & 17.79 & 17.64 & 480.1 & 362.3 & {$[45]$} \\
\hline $\mathrm{HoNi}_{2} \mathrm{~B}_{2} \mathrm{C}$ & 10 & 19.2 & - & 290 & 212 & [46] \\
\hline $\mathrm{Er}_{60} \mathrm{Co}_{20} \mathrm{Ni}_{20}$ & 11.5 & 15.5 & 15.2 & 403.2 & 320.3 & {$[47]$} \\
\hline $\mathrm{TmGa}$ & $11.5 / 15$ & 20.6 & - & - & 149 & {$[48]$} \\
\hline $\mathrm{Ho}_{2} \mathrm{BaCuO}_{5}$ & 12.5 & 10.4 & - & 263 & 199 & [49] \\
\hline $\mathrm{Tm}_{2} \mathrm{Cu}_{2} \mathrm{Cd}$ & 15 & 17.3 & - & 218 & 165 & {$[50]$} \\
\hline
\end{tabular}

genic MC materials [19,20,36,43-50] with magnetic ordering temperature $\left(T_{\mathrm{M}}\right)$ around $8 \mathrm{~K}$, for comparison. Evidently, the values of these $\mathrm{MC}$ parameters for $\mathrm{GdFe}_{2} \mathrm{Si}_{2}$ are much larger than those of $\mathrm{PrFe}_{2} \mathrm{Si}_{2}$ and $\mathrm{NdFe}_{2} \mathrm{Si}_{2}$ [36] and superior to those of most popular RE-based MC materials [19,20,43-50]. These results indicate that the presently studied $\mathrm{GdFe}_{2} \mathrm{Si}_{2}$ can be an excellent candidate material for cryogenic MR applications.

Additionally, a phenomenological constructed universal curve $[51,52]$ was proposed by normalizing the $-\Delta S_{M}(T)$ curve to the $-\Delta S_{\mathrm{M}}{ }^{\max }$ as $\Delta S^{\prime}\left(=\Delta S_{\mathrm{M}}(T) / \Delta S_{\mathrm{M}}{ }^{\mathrm{max}}\right)$ and by rescaling the temperature to $\left(T-T_{\text {peak }}\right) /\left(T_{\mathrm{r}}-T_{\text {peak }}\right)$ as $\theta$, which can be expressed as follows:

$\theta= \begin{cases}-\left(T-T_{\text {peak }}\right) /\left(T_{\mathrm{r} 1}-T_{\text {peak }}\right), & T \leq T_{\text {peak }} \\ \left(T-T_{\text {peak }}\right) /\left(T_{\mathrm{r} 2}-T_{\text {peak }}\right), & T>T_{\text {peak }},\end{cases}$

where $T_{\text {peak }}$ denotes the temperature of $-\Delta S_{\mathrm{M}}{ }^{\max }$, and $T_{\mathrm{r} 1}$ and $T_{\mathrm{r} 2}$ represent the temperatures of $\Delta S_{\mathrm{M}}$ equal to the $0.6 \times \Delta S_{\mathrm{M}}{ }^{\max }$ above and below the $T_{\mathrm{C}}$ for each $\Delta H$, respectively. Fig. $4 \mathrm{c}$ illustrates the rescaled $\Delta S^{\prime}(\theta)$ curves for $\mathrm{GdFe}_{2} \mathrm{Si}_{2}$. All the $\Delta S^{\prime}(\theta)$ curves collapsed into a single curve above the MPT, and distinct branches can be observed in the $\Delta S^{\prime}(\theta)$ curves below it, which further confirmed the existence of SO- and FO-MPTs for the studied $\mathrm{GdFe}_{2} \mathrm{Si}_{2}$ at different temperature zones.

The order of MPT can be checked by the novel MC criterion proposed by Law et al. [24,53,54], i.e., based on the field dependence exponent $n$ of the $\Delta S_{\mathrm{M}}(T)$ curves, which can be estimated using the following formula:

$n(T, H)=\frac{d \ln \left|\Delta S_{\mathrm{M}}\right|}{d \ln H}$.

Fig. $4 \mathrm{~d}-\mathrm{i}$ illustrate the temperature dependence of $-\Delta S_{\mathrm{M}}$ and exponent $n$ under different $\Delta H$ of $0-1,0-3$, and $0-5 \mathrm{~T}$ for $\mathrm{GdFe}_{2} \mathrm{Si}_{2}$. A previous investigation suggested that a clear overshoot of $n$ above 2 should exist in the $n(T)$ curves for an FOMPT material around its transition temperature [54]. For $\Delta H$ of $0-1 \mathrm{~T}$, an evident characteristic spike can be observed, as displayed in the shaded green zone, suggesting the switch from inverse to conventional MC effect. The $n$ value showed a small increase up to around 2 within the inverse-MC-effect region, and this result was ascribed to the ultralow MPT of $\mathrm{GdFe}_{2} \mathrm{Si}_{2}$ (Fig. $4 \mathrm{~d}, \mathrm{e}$ ). For $\Delta H$ of $0-3 \mathrm{~T}$, the overshoot feature ( $n$ above 2 ) can be noted at low temperatures, indicating the FO-MPT nat- ure (Fig. 4f, g). By comparison, no overshoot of $n>2$ was observed near the MPT for $\Delta H$ of $0-5 \mathrm{~T}$, indicating the SO-MPT nature (Fig. $4 \mathrm{~h}, \mathrm{i})$. Moreover, a minimum $n$ value below 1 typically existed around the transition temperature, which further confirmed that a single MPT occurred in the studied material [54]. These results are consistent with those obtained by the methods of Banerjee criterion and phenomenological universal curves.

\section{CONCLUSIONS}

In summary, a high-quality polycrystalline $\mathrm{GdFe}_{2} \mathrm{Si}_{2}$ has been successfully fabricated, and combined experimental and theoretical investigations have been performed with regard to its structural, magnetic, MPT, and MC properties. $\mathrm{GdFe}_{2} \mathrm{Si}_{2}$ revealed an unstable AFM interaction with a large magnetic moment in the ground state. Moreover, a huge reversible cryogenic MC effect and promising MC performances in $\mathrm{GdFe}_{2} \mathrm{Si}_{2}$ have been observed, accompanied by a magnetic fieldinduced FO-MPT. Outstanding MC performances at around Néel temperature $\left(T_{\mathrm{N}}\right)$ of $8.6 \mathrm{~K}$ have been realized in $\mathrm{GdFe}_{2} \mathrm{Si}_{2}$ with the $-\Delta S_{\mathrm{M}}^{\max }$, TEC(2), RC, and RCP values as high as $\quad 30.01 \mathrm{~J} \mathrm{~kg}^{-1} \mathrm{~K}^{-1}, \quad 29.37 \mathrm{~J} \mathrm{~kg}^{-1} \mathrm{~K}^{-1}, \quad 328.45 \mathrm{~J} \mathrm{~kg}^{-1}$, and $441.72 \mathrm{~J} \mathrm{~kg}^{-1}$ at the $\Delta H$ of $0-7 \mathrm{~T}$, respectively. Evidently, these MC parameters of $\mathrm{GdFe}_{2} \mathrm{Si}_{2}$ are better than those of most recently reported known cryogenic RE-based $\mathrm{MC}$ materials, making it attractive for practical cryogenic MR applications.

\section{Received 2 November 2021; accepted 11 January 2022;}

published online 11 February 2022

1 Li B, Kawakita Y, Ohira-Kawamura S, et al. Colossal barocaloric effects in plastic crystals. Nature, 2019, 567: 506-510

2 Cong D, Xiong W, Planes A, et al. Colossal elastocaloric effect in ferroelastic Ni-Mn-Ti alloys. Phys Rev Lett, 2019, 122: 255703

3 Wang Y, Wang L, Xia J, et al. Electric-field-driven non-volatile multistate switching of individual skyrmions in a multiferroic heterostructure. Nat Commun, 2020, 11: 3577

4 Hu L, Zhou J, Hou Z, et al. Polymer-buried van der Waals magnets for promising wearable room-temperature spintronics. Mater Horiz, 2021, 8: $3306-3314$

5 Liu J, Gottschall T, Skokov KP, et al. Giant magnetocaloric effect driven by structural transitions. Nat Mater, 2012, 11: 620-626

6 Franco V, Blázquez JS, Ipus JJ, et al. Magnetocaloric effect: From materials research to refrigeration devices. Prog Mater Sci, 2018, 93: 112- 
232

7 Zhang Y. Review of the structural, magnetic and magnetocaloric properties in ternary rare earth $\mathrm{RE}_{2} \mathrm{~T}_{2} \mathrm{X}$ type intermetallic compounds. $\mathrm{J}$ Alloys Compd, 2019, 787: 1173-1186

8 Li L, Yan M. Recent progresses in exploring the rare earth based intermetallic compounds for cryogenic magnetic refrigeration. J Alloys Compd, 2020, 823: 153810

9 Terada N, Mamiya $H$. High-efficiency magnetic refrigeration using holmium. Nat Commun, 2021, 12: 1212

$10 \mathrm{Hu} \mathrm{L}, \mathrm{Cao} \mathrm{L}$, Li L, et al. Two-dimensional magneto-photoconductivity in non-van der Waals manganese selenide. Mater Horiz, 2021, 8: 12861296

11 Ma Z, Dong X, Zhang Z, et al. Achievement of promising cryogenic magnetocaloric performances in $\mathrm{La}_{1-x} \mathrm{Pr}_{x} \mathrm{Fe}_{12} \mathrm{~B}_{6}$ compounds. J Mater Sci Tech, 2021, 92: 138-142

12 Law JY, Díaz-García Á, Moreno-Ramírez LM, et al. Increased magnetocaloric response of FeMnNiGeSi high-entropy alloys. Acta Mater, 2021, 212: 116931

13 Law JY, Franco V. Pushing the limits of magnetocaloric high-entropy alloys. APL Mater, 2021, 9: 080702

14 Lu X, Zhang Y, Wang F, et al. On the microstructural evolution and accelerated magnetocaloric phase formation in La-Fe-Si alloys by hot forging deformation. Acta Mater, 2021, 221: 117334

15 Ouyang Y, Zhang M, Yan A, et al. Plastically deformed La-Fe-Si: Microstructural evolution, magnetocaloric effect and anisotropic thermal conductivity. Acta Mater, 2020, 187: 1-11

16 Li Y, Qin L, Huang S, et al. Enhanced magnetocaloric performances and tunable martensitic transformation in $\mathrm{Ni}_{35} \mathrm{Co}_{15} \mathrm{Mn}_{35-x} \mathrm{Fe}_{x} \mathrm{Ti}_{15}$ all-dmetal Heusler alloys by chemical and physical pressures. Sci China Mater, 2022, 65: 486-493

17 Liu Y, Fu X, Yu Q, et al. Significant reduction of phase-transition hysteresis for magnetocaloric $\left(\mathrm{La}_{1-x} \mathrm{Ce}_{x}\right)_{2} \mathrm{Fe}_{11} \mathrm{Si}_{2} \mathrm{H}_{y}$ alloys by microstructural manipulation. Acta Mater, 2021, 207: 116687

18 Yin H, Law JY, Huang Y, et al. Enhancing the magnetocaloric response of high-entropy metallic-glass by microstructural control. Sci China Mater, 2021, doi: 10.1007/s40843-021-1825-1

$19 \mathrm{Li} \mathrm{L}, \mathrm{Xu} \mathrm{P}, \mathrm{Ye} \mathrm{S}$, et al. Magnetic properties and excellent cryogenic magnetocaloric performances in B-site ordered $\mathrm{RE}_{2} \mathrm{ZnMnO}_{6}(\mathrm{RE}=\mathrm{Gd}$, Dy and Ho) perovskites. Acta Mater, 2020, 194: 354-365

$20 \mathrm{Xu}$ P, Ma Z, Wang P, et al. Excellent cryogenic magnetocaloric performances in ferromagnetic $\mathrm{Sr}_{2} \mathrm{GdNbO}_{6}$ double perovskite compound. Mater Today Phys, 2021, 20: 100470

21 Li L, Yuan Y, Qi Y, et al. Achievement of a table-like magnetocaloric effect in the dual-phase $E_{2} \mathrm{n}_{2} / \mathrm{ErZn}_{\mathrm{n}}$ composite. Mater Res Lett, 2018, 6: $67-71$

22 Zhang $\mathrm{Y}, \mathrm{Wu} \mathrm{B}$, Guo D, et al. Magnetic properties and promising cryogenic magneto-caloric performances of $\mathrm{Gd}_{20} \mathrm{Ho}_{20} \mathrm{Tm}_{20} \mathrm{Cu}_{20} \mathrm{Ni}_{20}$ amorphous ribbons. Chin Phys B, 2021, 30: 017501

23 Zhang Y, Tian Y, Zhang Z, et al. Magnetic properties and giant cryogenic magnetocaloric effect in B-site ordered antiferromagnetic $\mathrm{Gd}_{2} \mathrm{MgTiO}_{6}$ double perovskite oxide. Acta Mater, 2022, 226: 117669

24 Guo D, Moreno-Ramírez LM, Romero-Muñiz C, et al. First- and second-order phase transitions in $\mathrm{RE}_{6} \mathrm{Co}_{2} \mathrm{Ga}$ ( $\mathrm{RE}=\mathrm{Ho}$, Dy or Gd) cryogenic magnetocaloric materials. Sci China Mater, 2021, 64: 2846-2857

25 Zhang Y, Zhu J, Li S, et al. Achievement of giant cryogenic refrigerant capacity in quinary rare-earths based high-entropy amorphous alloy. J Mater Sci Tech, 2022, 102: 66-71

26 Stockert O, Arndt J, Faulhaber E, et al. Magnetically driven superconductivity in $\mathrm{CeCu}_{2} \mathrm{Si}_{2}$. Nat Phys, 2011, 7: 119-124

$27 \mathrm{Wu} \mathrm{Z}$, Fang Y, Su H, et al. Revealing the heavy quasiparticles in the heavy-fermion superconductor $\mathrm{CeCu}_{2} \mathrm{Si}_{2}$. Phys Rev Lett, 2021, 127: 067002

28 Kim MS, Sung NH, Son Y, et al. Giant reversible anisotropic magnetocaloric effect in an antiferromagnetic $\mathrm{EuFe}_{2} \mathrm{As}_{2}$ single crystal. Appl Phys Lett, 2014, 98: 172509

29 Hou Z, Li L, Liu C, et al. Emergence of room temperature stable skyrmionic bubbles in the rare earth based $\mathrm{REMn}_{2} \mathrm{Ge}_{2}(\mathrm{RE}=\mathrm{Ce}, \mathrm{Pr}$, and Nd) magnets. Mater Today Phys, 2021, 17: 100341

30 Yang $\mathrm{X}, \mathrm{Gu} \mathrm{Y,} \mathrm{Li} \mathrm{Y,} \mathrm{et} \mathrm{al.} \mathrm{The} \mathrm{equivalent} \mathrm{and} \mathrm{aliovalent} \mathrm{dopants}$ boosting the thermoelectric properties of $\mathrm{YbMg}_{2} \mathrm{Sb}_{2}$. Sci China Mater, 2020, 63: 437-443

31 Li G, Wang J, Cheng Z, et al. Large entropy change accompanying two successive magnetic phase transitions in $\mathrm{TbMn}_{2} \mathrm{Si}_{2}$ for magnetic refrigeration. Appl Phys Lett, 2015, 106: 182405

32 Li L, Nishimura K, Hutchison WD, et al. Giant reversible magnetocaloric effect in $\mathrm{ErMn}_{2} \mathrm{Si}_{2}$ compound with a second order magnetic phase transition. Appl Phys Lett, 2012, 100: 152403

33 Felner I, Mayer I, Grill A, et al. Magnetic ordering in rare earth iron silicides and germanides of the $\mathrm{RFe}_{2} \mathrm{X}_{2}$ type. Solid State Commun, 1975, 16: $1005-1009$

34 Noakes DR, Umarji AM, Shenoy GK. Mössbauer studies of $\mathrm{REFe}_{2} \mathrm{Si}_{2}$ $(\mathrm{RE}=\mathrm{Gd}-\mathrm{Lu})$ compounds. J Magn Magn Mater, 1983, 39: 309-316

35 Liu ZS, Diviš M, Sechovský V. Magnetic and thermodynamic properties of $\mathrm{DyFe}_{2} \mathrm{Si}_{2}$ further investigated with crystal-field theory and two-ion model. J Phys Chem Solids, 2010, 71: 1447-1450

36 Ma Y, Dong X, Qi Y, et al. Investigation of the magnetic and magnetocaloric properties in metamagnetic $\mathrm{REFe}_{2} \mathrm{Si}_{2}(\mathrm{RE}=\mathrm{Pr}$ and $\mathrm{Nd})$ compounds. J Magn Magn Mater, 2019, 471: 25-29

37 Rodrigues-Carvajal J. FULLPROF. A Rietveld refinement and pattern matching analysis program (Laboratories Leon Brillouin (CEA-CNRS), France, 2000)

38 Evarestov RA, Smirnov VP. Modification of the Monkhorst-Pack special points meshes in the Brillouin zone for density functional theory and Hartree-Fock calculations. Phys Rev B, 2004, 70: 233101

39 Kresse G, Furthmüller J. Efficient iterative schemes for $a b$ initio totalenergy calculations using a plane-wave basis set. Phys Rev B, 1996, 54: 11169-11186

40 Perdew JP, Burke K, Ernzerhof M. Generalized gradient approximation made simple. Phys Rev Lett, 1996, 77: 3865-3868

41 Banerjee BK. On a generalised approach to first and second order magnetic transitions. Phys Lett, 1964, 12: 16-17

42 Griffith LD, Mudryk Y, Slaughter J, et al. Material-based figure of merit for caloric materials. J Appl Phys, 2018, 123: 034902

$43 \mathrm{Wu}$ B, Zhang Y, Guo D, et al. Structure, magnetic properties and cryogenic magneto-caloric effect $(\mathrm{MCE})$ in $\mathrm{RE}_{2} \mathrm{FeAlO}_{6}(\mathrm{RE}=\mathrm{Gd}$, Dy, Ho) oxides. Ceramics Int, 2021, 47: 6290-6297

44 Xu JW, Zheng XQ, Yang SX, et al. Giant low field magnetocaloric effect in TmCoSi and TmCuSi compounds. J Alloys Compd, 2020, 843: 155930

45 Zhang Y, Guo D, Wu B, et al. Magnetic properties and magneto-caloric performances in $\mathrm{RECo}_{2} \mathrm{~B}_{2} \mathrm{C}(\mathrm{RE}=\mathrm{Gd}, \mathrm{Tb}$ and $\mathrm{Dy})$ compounds. J Alloys Compd, 2020, 817: 152780

$46 \mathrm{Li} \mathrm{L}$. Review of magnetic properties and magnetocaloric effect in the intermetallic compounds of rare earth with low boiling point metals. Chin Phys B, 2016, 25: 037502

47 Wang Y, Guo D, Wu B, et al. Magnetocaloric effect and refrigeration performance in $\mathrm{RE}_{60} \mathrm{Co}_{20} \mathrm{Ni}_{20}$ ( $\mathrm{RE}=\mathrm{Ho}$ and $\mathrm{Er}$ ) amorphous ribbons. J Magn Magn Mater, 2020, 498: 166179

48 Yang SX, Zheng XQ, Yang WY, et al. Tunable magnetic properties and magnetocaloric effect of TmGa by Ho substitution. Phys Rev B, 2020, 102: 174441

49 Zhang Y, Li H, Wang J, et al. Structure and cryogenic magnetic properties in $\mathrm{Ho}_{2} \mathrm{BaCuO}_{5}$ cuprate. Ceramics Int, 2018, 44: 1991-1994

50 Zhang Y, Yang Y, Xu X, et al. Excellent magnetocaloric properties in $\mathrm{RE}_{2} \mathrm{Cu}_{2} \mathrm{Cd}(\mathrm{RE}=\mathrm{Dy}$ and $\mathrm{Tm})$ compounds and its composite materials. Sci Rep, 2016, 6: 34192

51 Franco V, Blázquez JS, Conde A. Field dependence of the magnetocaloric effect in materials with a second order phase transition: A master curve for the magnetic entropy change. Appl Phys Lett, 2006, 89: 222512

52 Franco V, Conde A. Scaling laws for the magnetocaloric effect in second order phase transitions: From physics to applications for the characterization of materials. Int J Refrigeration, 2010, 33: 465-473

53 Moreno-Ramírez LM, Law JY, Pramana SS, et al. Analysis of the magnetic field dependence of the isothermal entropy change of inverse magnetocaloric materials. Results Phys, 2021, 22: 103933

54 Law JY, Franco V, Moreno-Ramírez LM, et al. A quantitative criterion for determining the order of magnetic phase transitions using the 
magnetocaloric effect. Nat Commun, 2018, 9: 2680

Acknowledgements This work was financially supported by the National Natural Science Foundation of China (52071197), the "Pioneer" and "Leading Goose" R\&D Program of Zhejiang (2022C01230), the Science and Technology Committee of Shanghai Municipality (19ZR1418300 and 19DZ2270200), and the Independent Research and Development Project of State Key Laboratory of Advanced Special Steel, Shanghai Key Laboratory of Advanced Ferrometallurgy, Shanghai University (SKLASS 2021-Z05).

Author contributions Zhang Y designed the idea of the research. Zhu J, Li $S$ and Zhang $Y$ performed the experiments. Zhang $Z$ performed the theoretical calculations. Zhang Y, Zhang Z, Wang J and Ren Z performed the data analysis. Zhang $Y$ prepared the original manuscript. All the authors contributed to the general discussion and review and editing. Ren $\mathrm{Z}$ and Zhang $\mathrm{Y}$ contributed to the conceptualization and supervision.

Conflict of interest The authors declare that they have no conflict of interest.

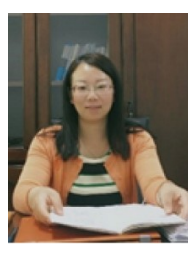

Yikun Zhang received her PhD degree from Northeastern University (China); afterward, she was granted by the Alexander von Humboldt (AvH) scholarship for postdoctoral research. Currently, she is a professor at the School of Electronics and Information Engineering, Hangzhou Dianzi University (China). Her research mainly focuses on designing and exploring magnetic functional materials, especially rare-earth-based magnetic refrigeration materials.

\section{反铁磁 $\mathrm{GdFe}_{2} \mathrm{Si}_{2}$ 化合物的磁性和低温磁热性能研究}

张义坤 $1,2,3^{*}$, 朱剑 ${ }^{2}$, 李硕 ${ }^{2}$, 张振乾 ${ }^{3}$, 王江 ${ }^{2}$, 任忠鸣 ${ }^{2}$

摘要 基于磁性材料相变过程中伴随的磁热效应而发展起来的磁制冷 技术因其绿色环保和高效节能等优点而被广泛关注. 高性能磁制冷工 质材料的探索一直是本领域的研究热点也是难点之一. 本文中, 我们通 过实验研究结合第一性原理计算, 对 $\mathrm{GdFe}_{2} \mathrm{Si}_{2}$ 化合物的晶体结构、磁 性、磁相变以及低温磁热效应进行了系统研究, 结果表明 $\mathrm{GdFe}_{2} \mathrm{Si}_{2}$ 化 合物基态为反铁磁且具有大的低温可逆磁热效应. 在0-7 T的磁场变化

下, 其磁制冷参数包括等温磁熵变最大值和制冷能力分别高达 $30.01 \mathrm{~J} \mathrm{~kg}^{-1} \mathrm{~K}^{-1}$ 和 $328.45 \mathrm{~J} \mathrm{~kg}^{-1}$. 这些磁制冷参数优于大多数目前已报 道的同温区高性能稀土基磁制冷材料, 表明反铁磁 $\mathrm{GdFe}_{2} \mathrm{Si}_{2}$ 化合物在 低温磁制冷领域同样具有潜在的应用前景. 